\title{
Peer review and services for elderly patients
}

\author{
M J Denham, D Lubel
}

An important feature of the white paper Working for Patients is medical audit. The Health Advisory Service which undertakes audit, was set up in 1969 by the then secretary of state, Richard Crossman, in response to the finding that patients had been abused in certain long stay hospitals. The service has a wide remit, which includes assessing and making recommendations on improving standards of care for those who are least able to fight on their own behalf-elderly and mentally ill patients. It is independent of the Department of Health and its director is responsible to only the Secretary of State for Health. The service is financed on a shoestring budget of $£ 1 \mathrm{~m}$ a year. The staff at the headquarters, comprising the director, his deputy, and 6.5 whole time staff equivalents costs $£ 200000$, and the remaining budget is used to finance the salaries, travel, and subsistence of team members and in producing reports.

Health districts are visited for three to four weeks by professional teams consisting of a consultant geriatrician or psychiatrist, or both; senior staff in the managerial, nursing, and rehabilitation services; and a senior representative from the Social Services Inspectorate. The service therefore undertakes multidisciplinary peer review. After each visit a public report is issued detailing the team's findings and recommendations.

Standards of care for elderly and mentally ill patients

As the Health Advisory Service aims at assessing and improving standards of care a review of its publications should produce a profile of current standards of care for elderly and mentally ill patients and of what has been achieved in improving them when they were deemed unsatisfactory. Unfortunately, the service's reports became public only within the past four years, before that they were confidential. Consequently, problems identified by the service in the early years can be discovered only from other sources, such as official inquiries and the service's annual reports.

Several official hospital inquiries that were set up to investigate serious allegations of neglect, poor management, and standards of care in psychiatric units $^{1}$ reported that the units concerned had been visited earlier by the Health Advisory Service. Visiting teams had correctly identified the problems and had offered appropriate advice, but in most cases this had been ignored or treated with patronising disdain or contempt.

The service's annual reports provide some specific information. The 1987 report is particularly valuable because it reviews 12 consecutive reports on services for elderly people. ${ }^{2}$ The service found that long stay wards consistently failed to provide privacy, homely

None of the 12 health districts visited had a comprehensive personalised laundry service and half lacked effective management of incontinence. Catering was often provided according to the needs of the institution rather than those of the patient. Privacy was often widely neglected, especially in toiletting, washing, and dressing. The amount of medical participation was often minimal.

Reports of visits by the Health Advisory Service are undoubtedly the best information source. Day et al reviewed 35 reports on services for elderly patients issued from July 1985 to December $1987,{ }^{3}$ and the table shows their findings together with the results of our own review of a further 30 reports produced from March 1988 to September 1989. Sanitary

Percentage of reports from Health Advisory Service highlighting various problems in long term care of elderly patients

\begin{tabular}{lcc}
\hline & $\begin{array}{c}\text { July } 1985 \\
\text { to December } \\
1987^{3}\end{array}$ & $\begin{array}{c}\text { March 1988 } \\
\text { to September } \\
1989\end{array}$ \\
\hline Poor sanitary conditions & 77 & 73 \\
Overcrowding in wards & 60 & 53 \\
Inadequate provision of day care & 37 & 40 \\
Use of restraints & 74 & 57 \\
Inadequate personal clothing & 66 & 53 \\
Poor communication among and within & & \\
professions & 83 & 73 \\
\hline
\end{tabular}

conditions continued to cause adverse comments in about three quarters of all visits. Reports mentioned patients being put on commodes in full view of others and toilets without doors or curtains. Half the reports commented on overcrowding in wards. Many units still use some form of restraint - for example, cot sides, restraining chairs, or locked ward doors. Half the units made excessive use of pooled clothing. In one ward patients were encouraged to stay in night clothes all day so that they could be easily identified if they escaped from the ward. Both reviews highlighted poor communication within and among professions, the worst case being when health authorities and social service departments did not discuss or plan together future services for elderly patients. One third of the reports criticised the authorities for inadequate inspection and monitoring of private rest and nursing homes and expressed concern about standards.

Many of the recommendations made in the reports required no extra funds but did need improved management and attitudes - for example, encouraging consultants to make regular visits to their long stay wards, toiletting patients in private, stopping locking patients out of their bedrooms because they might go to sleep there during the daytime, stopping the use of poor standard wards as punishment wards for difficult patients, and ensuring that drug prescriptions for patients in continued care are reviewed every few

Correspondence to:

BrMed f 1990;300: 1635-6 surroundings, and personal space for possessions. 
weeks instead of allowing one signature to last a patient's lifetime. Unfortunately, lack of published follow up data makes it impossible to find out what health authorities actually do as a result of the service's visits and recommendations.

\section{The future and the Health Advisory Service}

It is of concern that there seems to be little improvement in the frequency and types of problems regularly reported by visiting teams from the Health Advisory Service. What could be done to remedy this? Several options are possible: firstly, give the service executive power and agree guidelines for standards of care for patients in both public and private sectors; secondly, raise the profile of the service by highlighting problem areas, increasing the number of visits, and publishing follow up reports; and, thirdly, establish a research unit within the service to quantify and tabulate the very considerable amount of information collected by the service.

The service has a well established infrastructure, and if strengthened it could easily expand its work to help other medical specialties whose services are not easily assessed by current performance indicators. To avoid rivalries between specialties the director could be a general manager, advised by appropriate medical deputy directors

The prospects for the future of the service seem exciting, especially as its continued existence was supported by two recent reviews. ${ }^{3+}$ There are two important dark clouds on the horizon, however, in the form of the Audit Commission and the National Audit Office, which appear to be vying with each other to take over the work of the service. Both already assess and apply value for money judgments to many functions of the NHS. Such judgments are fairly easy to apply to standards of input but are difficult to apply to the attitudes of the staff and their patterns of practice, which can lead, for example, to patients being put on commodes in full view of others on the ward. Such practices may be detected only by night visits, which are a normal part of the routine of the service's teams. The Audit Commission and the National Audit Office seem to lack sufficient expertise in peer review to make judgments on the staff's attitudes and practices, which can have a large impact on patients' quality of life. Furthermore, the Audit Commission has been strongly criticised for presenting its facts in a way that makes it difficult to check or challenge them. ${ }^{6}$ The regional health authorities could also be groomed to take over the role of the service. Such an action would be costly, however, and would cause immense reduplication, be likely to have varying standards, and be unlikely to be truly independent. Surely what is needed is not a take over but a more authoritative higher profile service with executive power, which really would be working for patients in exactly the way the government intended.

1 Martin JP. Hospitals in trouble. Oxford: Blackwell, 1984.

2 Health Advisory Service. Annual report. Sutton: NHS Health Advisory Service, 1987

3 Day P, Klein R, Tipping S. Inspecting for quality. Bath: University of Bath, Centre for the Analysis of Social Policy, 1988

+ Henkel M, Kogan M, Parkwood T, Whitaker T, Youll P. The Health Advisor Service: an evaluation. London: King Edward's Hospital Fund, 1989.

5 Hudson R. Auditing's new issues. Health Service fournal 1989;99:1012-3.

6 McSweeney B. Accounting for the Audit Commission. Political Quarterly $1988: 59: 28-43$

(Accepted 14 Mav 1990)
Anton C de Groot, MD, dermatologist

On behalf of the working party European Community Affairs of the European Contact Dermatitis Society: a full list of members is given at the end of the paper

Correspondence to: Dr de Groot, Department of Dermatology, Carolus Hospital, PO Box 1101, 5200 BD 's-Hertogenbosch, The Netherlands.

Br Med f 1990;300:1636-8

\title{
Labelling cosmetics with their ingredients
}

\author{
Anton C de Groot
}

Dermatologists often see patients with contact dermatitis caused or worsened by cosmetic products. Adequate diagnosis, treatment, and advice are possible only if the offending ingredients can be identified. European Community regulations do not require cosmetics manufacturers to list all ingredients on their products; only about 30 groups of chemicals must be declared on the label. As an almost invariable consequence little information is provided on the product or package label. Doctors, therefore, often have to contact the manufacturers of the cosmetics used by their patients, which usually takes time and sometimes results in undesirable delays in diagnosis or no diagnosis at all. After the allergens responsible for the dermatitis have been identified patients need advice on which products to avoid and on those that can be used without risking a recurrence of dermatitis. Currently, this is virtually impossible.

The solution to this problem is simple: all ingredients of cosmetics and toiletries must be listed on the products or the package labels, or both. ${ }^{12}$

\section{Who would benefit?}

Listing the ingredients on the label would benefit patients who are allergic to cosmetics, dermatologists, and ultimately the cosmetic industry itself. It would allow dermatologists to use the appropriate tests to pinpoint the cause of contact dermatitis, and when a specific sensitiser had been identified they could advise the patient on which chemicals to avoid. This would apply not only to the causative allergens but also to cross reacting substances. Labelling would then allow the patient to choose cosmetics that would not provoke recurrences of allergic dermatitis. Labelling could also benefit patients presenting with complaints unrelated to cosmetics but who were found to be allergic to chemicals that are used in cosmetic products.

Furthermore, listing the ingredients of cosmetics would stimulate scientific investigations as it has done in the United States, ${ }^{3+}$ where labelling has been mandatory for over a decade.' It would allow the dermatological community to identify promptly new ingredients of cosmetics that cause problems. The lack of knowledge of the ingredients of cosmetics may delay the recognition of potential allergens for several years. ${ }^{5}$ Many patients are unnecessarily sensitised during this delay. Data generated by scientific studies on the allergens in cosmetics ${ }^{6}$ can be used by the cosmetics industry to make their products safer.

\section{How many would benefit?}

The number of patients allergic to cosmetics or their ingredients who would benefit from listing of the ingredients on labels seems to be sufficient to warrant the time and costs entailed in adapting European Community legislation.

\section{ALLERGY TO COSMETICS IN PATIENTS SEEN BY} DERMATOLOGISTS

In dermatological practice allergy to cosmetics has been diagnosed in $0.6 \%$ of all referrals and in approximately $5 \cdot 5 \%$ of all patients patch tested for 